\title{
COMPOSIÇÃO QUÍMICA E RESPIRAÇÃO DE CRESCIMENTO EM FRUTOS DE Psidium Cattleyanum SABINE DURANTE O CICLO DE DESENVOLVIMENTO ${ }^{1}$
}

\author{
ADRIANA SILVA GALHO ${ }^{2}$, NEI FERNANDES LOPES ${ }^{3}$, MARCOS ANTONIO BACARIN $^{4}$, MARIADA GRAÇAS DE SOUZALIMA
}

RESUMO- O experimento foi conduzido em condições de campo, sendo os frutos colhidos em araçazeiros de seis anos, crescidos no pomar da EMBRAPA- Clima Temperado. O objetivo foi determinar a composição química, a eficiência de conversão da glicose em novos compostos e a estimativa da respiração de crescimento de araçá ao longo da ontogenia do fruto. Os teores de macronutrientes decresceram ao longo do desenvolvimento do fruto. Os conteúdos de amido, carboidratos solúveis totais, açúcares redutores, lipídeos e ácidos orgânicos aumentaram, enquanto os teores de proteína e os componentes da parede celular diminuíram com a idade do fruto de araçá, principalmente na fase de maturação. Os carboidratos foram os maiores componentes orgânicos, fazendo com que o custo da respiração do fruto fosse baixo. $\mathrm{O}$ araçá foi eficiente na conversão de glicose em outros compostos orgânicos. $\mathrm{O}$ coeficiente de respiração de crescimento decresceu com a idade do fruto. A taxa de respiração de crescimento incrementou até a metade do período de crescimento acelerado do fruto.

Termos para indexação: Araçá, coeficientes de respiração de crescimento e eficiência de conversão de açúcares.

\section{CHEMICAL COMPOSITION AND GROWTH RESPIRATION IN Psidium cattleyanum SABINE FRUITS DURING THE DEVELOPMENT CYCLE}

\begin{abstract}
The experiment was carried out under field conditions, where the fruits were harvest in Brazilian guava trees with six years old, growing on orchard of EMBRAPA- Temperate weather. The aim of the research was to determine the chemical composition, the efficiency of glucose conversion in new compounds and growth respiration estimate of the fruits during its ontogeny. The macronutrients content decreased with fruit development cycle. The contents of starch, total soluble sugars, reduced sugars, lipids and organic acids augmented as the fruits aged, while the protein contents and the components of cell wall decreased during fruit ontogeny, with strong accumulation during ripening. The carbohydrates were the major organic compounds, determining low cost of fruit respiration. The Brazilian guava showed to be an efficient fruit on glucose conversion in other organic compounds. The respiratory coefficient decreased as the fruit aged. The growth respiration rate increased until the middle of accelerate growth phase of the fruit.
\end{abstract}

Index terms: Brazilian guava, growth respiration coefficients and efficiency of sugars conversion.

\section{INTRODUÇÃO}

Atualmente, na produção vegetal, deve ser considerada tanto a quantidade quanto a qualidade do alimento. O conhecimento da composição química dos alimentos é fundamental para a nutrição humana. $\mathrm{O}$ fruto de araçá possui alto teor de vitamina $C$, em geral 3 a 4 vezes maior do que os frutos cítricos (Raseira \& Raseira, 1996). Por outro lado, a determinação dos componentes orgânicos e inorgânicos da biomassa de órgãos ou da planta inteira, ao longo do desenvolvimento, é de suma importância para o entendimento de processos metabólicos e nutricionais do próprio vegetal.

Os frutos de todas as cultivares de $P$. cattleyanum e $P$. guajava são climatéricos no seu comportamento respiratório (Akamine \& Goo, 1979). Fisiologicamente, a respiração é o processo pelo qual compostos altamente energéticos (ATP) e redutores $\left(\mathrm{NADH}_{2}\right)$ são formados a partir de carboidratos ou outros substratos. Esses compostos (ATP e $\mathrm{NADH}_{2}$ ) são utilizados essencialmente em síntese de novas substâncias. Desse modo, a respiração pode ser vista como acoplada à síntese de novos tecidos (respiração de crescimento) e à manutenção estrutural (respiração de Manutenção) por meio do "turnover" de ATP e $\mathrm{NADH}_{2}$, necessária para o crescimento vegetal.

A eficiência de conversão $\left(\mathrm{Y}_{\mathrm{G}}\right)$ pode ser definida como a quantidade de constituintes químicos produzidos por unidade de substrato, podendo ser estimada a partir de dados sobre eficiência de crescimento, conteúdo bioquímico ou calor de combustão. Desse modo, quando não há custo para a respiração de crescimento, $\mathrm{Y}_{\mathrm{G}}$ é máximo $\left(\mathrm{Y}_{\mathrm{G}}=1\right)$, quanto menor for $\mathrm{Y}_{\mathrm{G}}$ mais alto é o custo da respiração de crescimento. $O$ cálculo da massa do novo material que pode ser formado desde uma massa unitária de substrato com a utilização de oxigênio, minerais, produção de água e gás carbônico, foi denominado de "Bioquímica Quantitativa” por Penning de Vries et al. (1974).

Este trabalho teve como objetivo determinar a composição química, a eficiência de conversão da glicose em novos materiais

' (Trabalho 082-2005).Recebido em : 09-05-2005. Aceito para publicação: 03-12-2006 . Parte da Dissertação apresentada à UFPel pela primeira autora para obtenção do título de Mestre em Ciências.

${ }^{2}$ Biol. M.S, Professora Assistente da UCPel, Rua Félix da Cunha , C.P.412, 96010-000, Pelotas-RS, adrianagalho@ig.com.br.

${ }^{3}$ Eng. Agro, Ph..D., Professor Titular, Dep. De Botânica, UFPel, C.P. 354, 96010-900, Pelotas-RS, neilopes@ufpel.tche.br.

${ }^{4}$ Eng. Agro, D.S., Professor Adjunto, Bolsista CNPq, Dep. De Botânica, UFPel, C.P. 354 , 96010-900, Pelotas-RS.

${ }^{5}$ Eng. Agro, M.S., Bolsista CAPES, Doutoranda do PPGFV, Dep. De Botânica, UFPel, C.P. 354 , 96010-900, Pelotas-RS. 
e a estimativa da respiração acoplada ao crescimento do fruto de araçá ao longo de sua ontogenia.

\section{MATERIAL E MÉTODOS}

O experimento foi conduzido em condições de campo, entre outubro de 1996 a março de 1997, sendo utilizadas plantas de Psidium cattleyanum Sabine, clone Amarelo Rio Grande, com seis anos de idade, crescida no pomar da EMBRAPA - Clima Temperado, localizado em Pelotas-RS. O clima da região é Cfa pela classificação de Köppen. A topografia do terreno é levemente ondulada, sendo o solo classificado como Podzólico VermelhoAmarelo-distrófico textura argilosa, com baixa fertilidade. $\mathrm{O}$ solo recebeu três adubações: agosto/setembro: 100-120g de superfosfato triplo e 150-200g de sulfato de amônia ou nitrato de cálcio; novembro/dezembro: 100 - $150 \mathrm{~g}$ de nitrato de cálcio e em março/abril: $100 \mathrm{~g}$ de nitrato de cálcio ou sulfato de amônia por planta. As temperaturas máximas, mínimas e médias, a umidade relativa do ar, bem como a precipitação pluvial enquadraram-se dentro das normais da região. Não foi necessário suplementação de água por irrigação (Galho et al.,2000).

O delineamento experimental foi inteiramente ao acaso, sendo os tratamentos constituídos por nove coletas sucessivas de 40 frutos por araçazeiro, colhidos dez em cada quadrante (norte, sul, leste e oeste), em cinco árvores (repetições). As coletas foram realizadas a intervalos regulares de 14 dias, a partir de 10 dias após a antese (DAA), durante a ontogenia dos frutos (Galho et al.,2000).

A massa fresca dos frutos foi determinada gravimetricamente. Posteriormente, a massa seca foi obtida em estufa de ventilação forçada, à temperatura de $75 \pm 2{ }^{\circ} \mathrm{C}$, até massa constante. A massa seca dos frutos, em cada época de colheita, foi moída em moinho tipo Willey, com peneira de 20 mesh acondicionada em vidros para posterior análise.

As determinações químicas foram efetuadas em cinco amostras por araçazeiro, perfazendo 25 análises para cada coleta, totalizando 225 quantificações por substância nas nove coletas. Para a determinação do nitrogênio, amostras foram submetidas à digestão sulfúrica (Lindner, 1944) e dosado pelo método de Nessler (Umbreit et al., 1972), e para as de fósforo, potássio, cálcio e magnésio, as amostras foram submetidas à digestão nitroperclórica, de acordo com Johnson \& Ulrich (1959) e Jorgensen (1977). O teor de fósforo foi determinado colorimetricamente pela redução do complexo fosfomolíbdico, conforme o método proposto por Braga \& Defelipo (1974); o de potássio, por fotometria de emissão de chama, e os de cálcio e magnésio, por espectrofotometria de absorção atômica recomendada pela AOAC (1975).

Os carboidratos solúveis totais foram determinados em cinco amostras de $200 \mathrm{mg}$ de frutos por repetição, pelo método da antrona (Clegg, 1956). Do resíduo dos centrifugados, após a extração dos açúcares, foi determinado o amido pelo método de McCready et al. (1950). Os lipídios foram determinados em amostras de 3,0 g de frutos, colocada em papel-filtro, embrulhada em forma de cartucho e extraída num Sohxlet, com éter de petróleo, por seis horas (Instituto Adolfo Lutz, 1985). A proteína bruta total foi calculada multiplicando o teor de nitrogênio total por
6,25 . Os componentes da parede celular ( celulose, hemicelulose, lignina e sílica mais cinzas) foram determinados pelo método de Van Söest (1963, 1965 e 1967). Enquanto a determinação dos ácidos orgânicos, expressos em porcentagem de ácido oxaloacético (AOA), foi realizada em amostras de $1,0 \mathrm{~g}$ de matéria seca dos frutos em $100 \mathrm{~mL}$ de água e, após agitação e repouso por duas horas, foram filtrados e efetuadas titulações sob agitação com solução de $\mathrm{NaOH}$ a $0,1 \mathrm{~N}$, até pH 8,0. Os cálculos foram efetuados pela equação: $\mathrm{AOA} \%=(\mathrm{Vb}$. N. 66. 0,1)/ Va, sendo $\mathrm{Va}$ e $\mathrm{Vb}$ os volumes da amostra e da base $(\mathrm{mL}), \mathrm{N}$ a normalidade da base $\left(\mathrm{e}_{\mathrm{f}} \cdot \mathrm{g} \cdot \mathrm{L}^{-1}\right), 66$ o equivalente grama do AOA e 0,1 fator de conversão correspondente a: $100 \times 1 \mathrm{~mL} / 1000 \mathrm{~mL}$ ) (Pruthi, 1938).

Tomando por base a bioquímica quantitativa de Penning de Vries (1975a, b), Penning de Vries et al. (1974) e Penning de Vries \& Van Laar (1982), foi estimada a quantidade, em gramas de glicose (Gs) necessária para a formação de um grama de material vegetal, com o emprego da equação:

$\mathrm{Gs}=(1,25 \mathrm{CH}+1,67 \mathrm{PR}+2,85 \mathrm{EE}+1,10 \mathrm{AO}+2,08 \mathrm{LG}+0,93 \mathrm{AN})$ sendo $\mathbf{C H}$ os carboidratos, $\mathbf{P R}$ as proteínas, EE o extrato etéreo, AO os ácidos orgânicos, LG a lignina e $\mathbf{A N}$ os ácidos nucléicos. Para estes cálculos, as quantidades de todos os componentes da biomassa foram expressos em $\mathrm{g} \mathrm{g}^{-1}$ de matéria seca.

A quantidade total de glicose $\left(\mathbf{G}_{\mathbf{S T}}\right)$ por fruto foi obtida por: $\mathrm{G}_{\mathrm{ST}}=\mathrm{Gs} \mathrm{W}_{\mathrm{f}}$, sendo $\mathbf{G}_{\mathrm{s}}$ a quantidade total de glicose utilizada para a formação do fruto $\left(\mathrm{g}\right.$ fruto $\left.^{-1}\right) \mathrm{e} \mathbf{W}_{\mathbf{f}}$ a matéria seca do fruto $\left(\mathrm{g}\right.$ fruto $^{-1}$ ).

A eficiência global de conversão do processo construtivo de respiração $\left(\mathbf{Y}_{\mathbf{G}}\right)$ foi calculada por $\mathrm{Y}_{\mathrm{G}}=\mathrm{G}_{\mathrm{S}}^{-1}$. O substrato respiratório de crescimento $\left(\mathbf{S}_{\mathbf{R G}}\right)$, em termos de glicose respirada ( $\mathrm{g}$ de glicose $\mathrm{g}^{-1} \mathrm{MS}$ ), foi estimado pela fórmula:

$\mathrm{S}_{\mathrm{RG}}=(0,25 \mathrm{CH}+0,67 \mathrm{PR}+1,85 \mathrm{EE}+0,10 \mathrm{AO}+1,08 \mathrm{LG}-0, \mathrm{O} 7 \mathrm{AN})$.

A taxa de substrato respiratório de crescimento $\left(\mathrm{S}_{\mathrm{RG}}{ }\right)$ foi obtida: $\mathrm{S}_{\mathrm{RG}}{ }_{\mathrm{RG}}=\mathrm{S}_{\mathrm{RG}} \mathrm{dW} / \mathrm{dt}$, multiplicando o substrato respiratório de crescimento $\left(S_{\mathrm{RG}}\right)$ pela taxa de crescimento do fruto. $\mathrm{O}$ coeficiente de respiração de crescimento $\left(\mathrm{G}_{\mathrm{R}}\right)$, expresso pela quantidade $\mathrm{CO}_{2}$ liberado, foi calculado pela equação: $\mathrm{G}_{\mathrm{R}}=264$ $\mathrm{S}_{\mathrm{RG}} / 180$, pois $1 \mathrm{~mol}$ de glicose $(180 \mathrm{~g})$ libera 6 moles de $\mathrm{CO}_{2}$ (264g).

A taxa de respiração de crescimento $\left(\mathbf{T}_{\mathbf{R G}}\right)$, expressa pela quantidade de $\mathrm{CO}_{2}$ liberado por fruto por dia, foi estimada por: $\mathrm{T}_{\mathrm{RG}}=\mathrm{G}_{\mathrm{R}} \mathrm{dW} / \mathrm{dt}$.

\section{RESULTADOS E DISCUSSÃO}

Os teores dos macronutrientes (cálcio, fósforo, potássio, magnésio e nitrogênio) dos frutos decresceram ao longo da ontogenia do fruto de araçá (Figura 1). Na fase inicial de crescimento do fruto, primeiros $38 \mathrm{DAA}$, ocorreu acúmulo maior de todos os elementos minerais determinados, seguido de uma queda nos teores durante a fase de crescimento acelerada do fruto (38 a 80 DAA); posteriormente, houve redução nos teores dos constituintes minerais na fase de maturação do fruto, em virtude, provavelmente, do efeito de diluição durante o ciclo de desenvolvimento do araçá. Dentre os macronutrientes, verificouse maior teor do elemento nitrogênio, seguido de potássio, cálcio, magnésio e fósforo (Figura 1). 
O teor de proteína decresceu com a idade do fruto (Tabela 1), e esta tendência pode ser atribuída ao fato de que tecidos jovens, normalmente, possuem maiores proporções de protoplasma, em relação à matéria seca. $\mathrm{O}$ conteúdo protéico foi relativamente alto $\left(93 \mathrm{mg} \mathrm{g}^{-1}\right)$ na fase inicial do crescimento do fruto (primeiros $24 \mathrm{DAA}$ ), e após esse período houve diminuição nesse teor, permanecendo praticamente constante na fase de crescimento acelerado (38 aos 80 DAA), ocorrendo a seguir uma queda até a colheita final $\left(39,8 \mathrm{mg} \mathrm{g}^{-1}\right)$, fase de maturação do fruto. Enquanto o fruto de goiaba tem uma composição protéica média no fruto maduro de 1,06\% (Wilson, 1980), variando numa faixa compreendida entre 0,8 a 1,5\% de proteína crua (Rathore, 1976), foi encontrado no fruto de araçá 2,5 vezes mais de proteína crua.

O teor de lipídios do fruto de araçá é muito pequeno nos primeiros 80 DAA (Tabela 1), fase inicial e fase acelerada do crescimento do fruto, aumentando expressivamente o acúmulo na fase de maturação (após 94 DAA). Os frutos de araçá na colheita final mostraram um conteúdo de gordura dentro da faixa de 0,4 a $0,7 \%$ apresentada por Rathore (1976) e semelhante a 0,36\% para frutos de goiaba (WiIson, 1980).

$\mathrm{O}$ teor de amido em frutos de araçá aumentou levemente durante as fases inicial e de crescimento acelerado (de 10 aos 80 DAA), incrementando fortemente o acúmulo de amido na fase de maturação do fruto (de 94 aos 122 DAA) (Tabela 1). Por outro lado, os teores de carboidratos solúveis totais em frutos de araçá (Tabela 1) praticamente se mantiveram constantes na fase inicial de crescimento até os 52 DAA. Na fase de crescimento acelerado, o conteúdo de carboidratos solúveis totais aumentou em 2,26 vezes e duas vezes mais na fase de maturação do araçá. Da mesma forma, os teores de açúcares redutores em frutos de araçá (Tabela 1) tiveram um comportamento semelhante aos dos carboidratos solúveis totais, aumentando paulatinamente até os 66 DAA e acelerando o acúmulo de açúcares redutores a partir de 80 DAA até a maturação final do fruto. Comparando os teores de açúcares redutores e carboidratos solúveis totais determinados em frutos de araçá com os encontrados em frutos de goiaba por WiIson (1980) e Paiva et al. (1997), constata-se que os araçás possuem menor teor de açúcares do que as goiabas.

Os componentes da parede celular ao longo da ontogenia do fruto de araçá são mostrados na Tabela 1. O teor de celulose aumentou até os 52 DAA, mantendo-se constante de 52 a 80 DAA, reduzindo o seu conteúdo ao valor inicial e permanecendo constante durante a fase de maturação (de 94 a 122 DAA). A hemicelulose aumentou até os 24 DAA, mostrando uma queda gradativa até a fase final de maturação, sendo que o seu conteúdo foi reduzido à metade do valor inicial. O conteúdo de lignina caiu gradativamente da fase inicial de crescimento do fruto à colheita final, onde atingiu $25 \%$ do teor inicial. O teor de cinzas cresceu gradativamente até a fase final do crescimento acelerado, daí decrescendo e mantendo-se constante na fase de maturação do fruto (de 94 a 122 DAA).

O teor de ácidos orgânicos (AO) aumentou lentamente nas fases iniciais de crescimento do fruto de araçá, ficando praticamente constante até os 52 DAA. Posteriormente, houve aceleração no acúmulo de ácidos orgânicos, atingindo o máximo de $12,95 \mathrm{mg} \mathrm{g}^{-1}$ aos 94 DAA, fase de crescimento acelerado do fruto. $\mathrm{Na}$ fase de maturação do araçá, o conteúdo de ácidos orgânicos diminuiu até atingir o valor de $9,53 \mathrm{mg} \mathrm{g}^{-1}$ na colheita final (Tabelas 1 e 2). Comparando o teor de ácidos orgânicos determinados em frutos de araçá com acidez da goiaba, fruto caracterizado como moderadamente ácido (Czyhrinciw, 1969), denota-se que os frutos de Psidium cattleyanum clone Amarelo Rio Grande são mais ácidos do que os de várias cultivares de Psidium guajava (Wilson, 1980; Pinheiro et al., 1984; Nascimento et al., 1991; Paiva et al., 1997)

Os açúcares solúveis totais (AST) mantiveram-se praticamente constantes até os 52 DAA, incrementando acentuadamente o seu teor até a colheita final (Tabelas 1 e 2). A razão AST/AO (Tabela 2) ficou em um nível praticamente sem oscilação até 66 DAA, metade da fase de crescimento acelerado, baixando o valor na fase subseqüente de crescimento acelerado do fruto (de 80 a 94 DAA), voltando a aumentar na fase de maturação. Em goiaba, a razão açúcares/ácidos orgânicos é de 10,1 (Wilson, 1980). A razão açúcares/ácidos orgânicos, em goiaba, varia de 4 a 25, e a relação Brix/ácido, de 5 a 53, sendo muito variáveis (Ogata et al., 1972). A razão AST/AO determinada na maturação do fruto de araçá foi de 9,09 (108 DAA) e 11,09 (122 DAA), sendo similar à encontrada em frutos de goiaba por Wilson (1980).

TABELA 1 - Concentração de compostos orgânicos em função da ontogenia de frutos de araçá

\begin{tabular}{|c|c|c|c|c|c|c|c|c|c|}
\hline \multicolumn{10}{|c|}{ Concentração $\left(\mathrm{mg} \mathrm{g}^{-1}\right)$} \\
\hline \multirow[t]{2}{*}{ Compostos } & \multicolumn{9}{|c|}{ Dias após a antese } \\
\hline & 10 & 24 & 38 & 52 & 66 & 80 & 94 & 108 & 122 \\
\hline Proteína & $93,6 \pm 4,7$ & $93,0 \pm 5,4$ & $74,2 \pm 4,9$ & $66,7 \pm 4,7$ & $67,2 \pm 4,4$ & $64,5 \pm 4,4$ & $53,8 \pm 4,5$ & $44,1 \pm 3,3$ & $39,8 \pm 3,1$ \\
\hline Lipídeos & - & - & $0,03 \pm 0,01$ & $0,06 \pm 0.01$ & $0,15 \pm 0,02$ & $0,28 \pm 0,03$ & $0,92 \pm 0,06$ & $3,77 \pm 0,25$ & $4,42 \pm 0,34$ \\
\hline Amido & $6,8 \pm 0,6$ & $10,3 \pm 0,9$ & $10,3 \pm 1,1$ & $10,0 \pm 1,0$ & $13,9 \pm 1,3$ & $16,1 \pm 1,5$ & $94,7 \pm 6,4$ & $101,3 \pm 8,1$ & $89,2 \pm 6,7$ \\
\hline $\mathrm{CST}^{*}$ & $19,3 \pm 1,4$ & $23,1 \pm 2,0$ & $20,2 \pm 1,3$ & $22,7 \pm 1,6$ & $45,0 \pm 3,4$ & $52,2 \pm 3,7$ & $88,6 \pm 7,0$ & $101,3 \pm 9,1$ & $105,7 \pm 10,6$ \\
\hline $\mathrm{AR}^{*}$ & $9,0 \pm 0,7$ & $12,1 \pm 1,1$ & $10,5 \pm 0,8$ & $12,8 \pm 1,3$ & $16,4 \pm 2,3$ & $14,1 \pm 1,8$ & $21,4 \pm 2,0$ & $25,3 \pm 2,2$ & $26,0 \pm 2,4$ \\
\hline Celulose & $23,4 \pm 1,6$ & $26,3 \pm 1,9$ & $27,2 \pm 2,1$ & $32,8 \pm 3,1$ & $29,1 \pm 2,0$ & $30,9 \pm 2,9$ & $23,4 \pm 1,7$ & $23,8 \pm 1,5$ & $25,3 \pm 1,8$ \\
\hline Hemicelulose & $16,3 \pm 0,8$ & $25,4 \pm 2,0$ & $22,3 \pm 1,8$ & $20,6 \pm 1,4$ & $21,9 \pm 1,7$ & $19,061,3$ & $14,7 \pm 1,0$ & $8,8 \pm 0,6$ & $9,7 \pm 0,8$ \\
\hline Lignina & $18,4 \pm 0,9$ & $13,3 \pm 0,7$ & $10,9 \pm 0,9$ & $9,7 \pm 0,6$ & $10,9 \pm 1,0$ & $8,3 \pm 0,6$ & $7,5 \pm 0,6$ & $4,7 \pm 0,4$ & $2,8 \pm 0,3$ \\
\hline Cinzas & $2,8 \pm 0,3$ & $6,3 \pm 0,7$ & $6,4 \pm 0,9$ & $7,2 \pm 0,8$ & $9,6 \pm 0,9$ & $13,8 \pm 1,3$ & $7,5 \pm 0,8$ & $6,8 \pm 0,6$ & $7,3 \pm 0,7$ \\
\hline $\mathrm{AO}^{*}$ & $2,1 \pm 0,1$ & $2,7 \pm 0,2$ & $2,9 \pm 0,2$ & $3,2 \pm 0,2$ & $5,3 \pm 0,4$ & $8,8 \pm 0,7$ & $12,9 \pm 1,1$ & $11,2 \pm 1,0$ & $9,5 \pm 0,9$ \\
\hline
\end{tabular}

* CST= carboidratos solúveis totais, $\mathrm{AR}=$ açúcares redutores, $\mathrm{AO}=$ ácidos orgânicos 
TABELA 2 - Conteúdo de açúcares solúveis totais (AST), ácidos orgânicos (AO) e sua relação (AST/AO) durante a ontogenia dos frutos de araçá

\begin{tabular}{cccc}
\hline DAA & AST\% & AO $^{*} \%$ & AST/AO \\
\hline 10 & $1,93 \pm 0,14$ & $0,214 \pm 0,013$ & $9,02 \pm 0,60$ \\
24 & $2,30 \pm 0,20$ & $0,271 \pm 0,019$ & $8,49 \pm 0,66$ \\
38 & $2,02 \pm 0,13$ & $0,287 \pm 0,017$ & $7,04 \pm 0,44$ \\
52 & $2,30 \pm 0,16$ & $0,323 \pm 0,023$ & $7,15 \pm 0,47$ \\
66 & $4,50 \pm 0,34$ & $0,529 \pm 0,042$ & $8,51 \pm 0,66$ \\
80 & $5,20 \pm 0,37$ & $0,877 \pm 0,072$ & $5,93 \pm 0,46$ \\
94 & $8,80 \pm 0,70$ & $1,294 \pm 0,111$ & $6,80 \pm 0,56$ \\
108 & $10,13 \pm 0,91$ & $1,115 \pm 0,104$ & $9,09 \pm 0,83$ \\
122 & $10,57 \pm 1,06$ & $0,953 \pm 0,093$ & $11,09 \pm 1,10$ \\
\hline Média & $5,31 \pm 0,45$ & $0,651 \pm 0,055$ & $8,12 \pm 0,64$
\end{tabular}

Expresso em ácido oxaloacético

TABELA 3 - Estimativas das quantidades de glicose para formar um grama de biomassa $\left(\mathrm{G}_{\mathrm{S}}\right)$, a biomassa total do fruto $\left(\mathrm{G}_{\mathrm{ST}}\right)$, eficiência de conversão $\left(\mathrm{Y}_{\mathrm{G}}\right)$, substrato respiratório de crescimento $\left(\mathrm{S}_{\mathrm{RG}}\right)$, taxa de substrato respiratório de crescimento $\left(\mathrm{S}_{\mathrm{RG}}{ }_{\mathrm{RG}}\right)$ e coeficiente de respiração de crescimento $\left(\mathrm{G}_{\mathrm{R}}\right)$ de araçá durante a ontogenia dos frutos

\begin{tabular}{lcccccc}
\hline DAA & $\begin{array}{c}\text { GS } \\
\text { g glic/gMS }\end{array}$ & $\begin{array}{c}\text { GST } \\
\text { g glic/fruto }\end{array}$ & $\begin{array}{c}\text { YG } \\
\text { g/g }\end{array}$ & $\begin{array}{c}\text { SRG } \\
\text { g glic/gMS }\end{array}$ & $\begin{array}{c}\text { S'RG } \\
\text { glic/fru.d }\end{array}$ & $\begin{array}{c}\text { GR } \\
\text { g CO }_{2} / \text { gMS }\end{array}$ \\
\hline 10 & 1,34 & 0,62 & 0,75 & 0,36 & 0,059 & 0,53 \\
24 & 1,30 & 0,98 & 0,77 & 0,36 & 0,091 & 0,53 \\
38 & 1,23 & 1,46 & 0,81 & 0,29 & 0,109 & 0,43 \\
52 & 1,22 & 2,22 & 0,82 & 0,29 & 0,147 & 0,43 \\
66 & 1,20 & 3,14 & 0,83 & 0,29 & 0,183 & 0,43 \\
80 & 1,22 & 4,30 & 0,82 & 0,27 & 0,178 & 0,40 \\
94 & 1,32 & 5,88 & 0,76 & 0,28 & 0,174 & 0,41 \\
108 & 1,21 & 6,32 & 0,83 & 0,28 & 0,138 & 0,41 \\
122 & 1,20 & 7,00 & 0,83 & 0,27 & 0,099 & 0,40 \\
\hline Média & 1,25 & 3,55 & 0,80 & 0,30 & 0,131 & 0,44 \\
\hline
\end{tabular}

Em termos absolutos, a quantidade de glicose para a produção da biomassa total do fruto $\left(\mathrm{G}_{\mathrm{ST}}\right)$ aumentou durante o ciclo de desenvolvimento do araçá (Tabela 3). Enquanto a quantidade de glicose utilizada para formar um grama de novo material $\left(\mathrm{G}_{\mathrm{S}}\right)$ foi mais alta na fase inicial do crescimento do araçá, usando de 1,34 e 1,30 g glicose $\mathrm{g}^{-1} \mathrm{MS}$, alcançados aos 10 e 24 DAA, nessa fase, o fruto apresentou teor protéico maior, justificando um gasto mais elevado. Durante a fase de crescimento acelerado (de 38 a 80 DAA), $\mathrm{G}_{\mathrm{S}}$ foi praticamente constante, com valores em torno de $1,22 \mathrm{~g}_{\text {glicose }} \mathrm{g}^{-1} \mathrm{MS}$. Houve incremento em $\mathrm{G}_{\mathrm{S}}\left(1,32 \mathrm{~g}\right.$ glicose $\left.\mathrm{g}^{-1} \mathrm{MS}\right)$ aos 94 DAA, devido ao aumento no teor protéico, provavelmente ocasionado pelo crescimento das

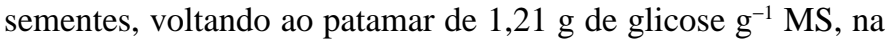
fase final de maturação do fruto. Como a composição química do fruto mostrou que o araçá contém grande quantidade de carboidratos em relação a outros materiais orgânicos, em média, foi necessário 1,25 g de glicose consumida por $\mathrm{g}$ de massa seca produzida ao longo do ciclo de desenvolvimento do araçá.

A eficiência global de conversão do processo construtivo de respiração $\left(\mathrm{Y}_{\mathrm{G}}\right)$ mostrou que o araçá é um fruto eficiente na conversão de glicose em outros compostos orgânicos, pois, ao longo do seu desenvolvimento, teve um $\mathrm{Y}_{\mathrm{G}}$ médio de 0,80 (Tabela 3). Na fase inicial de crescimento, onde o fruto era mais rico em proteína, o custo de conversão foi mais elevado, ou seja, 0,75 a $0,76 \mathrm{~g} \mathrm{~g}^{-1}$. Na fase acelerada de crescimento (de 38 a 80 DAA), $\mathrm{Y}_{\mathrm{G}}$ foi constante com valor de $0,82 \mathrm{~g} \mathrm{~g}^{-1}$. A eficiência de conversão caiu para $0,76 \mathrm{~g} \mathrm{~g}^{-1}$ (94 DAA), possivelmente em virtude da elevação no teor protéico, voltando ao valor de $0,83 \mathrm{~g} \mathrm{~g}^{-1}$ nos estádios finais do crescimento do fruto.

O substrato respiratório de crescimento $\left(\mathrm{S}_{\mathrm{RG}}\right)$ foi de 0,36 g glicose $\mathrm{g}^{-1} \mathrm{MS}$ na fase inicial do crescimento do fruto e mantevese praticamente constante $\left(0,28 \mathrm{~g}_{\text {glicose }} \mathrm{g}^{-1} \mathrm{MS}\right)$ nos estádios subseqüentes de crescimento do fruto, com valor médio de 0,30 g glicose $\mathrm{g}^{-1} \mathrm{MS}$ para todo o ciclo de desenvolvimento do araçá (Tabela 3). No entanto, a taxa de substrato respiratório de crescimento dos frutos $\left(\mathrm{S}_{\mathrm{RG}}{ }\right)$ aumentou durante as fases iniciais do crescimento até aproximadamente a metade da fase de crescimento acelerado, atingindo o valor máximo de $183 \mathrm{mg}$ glicose $\mathrm{g}^{-1} \mathrm{MS} \mathrm{dia}^{-1}$, aos 66 DAA, decaindo gradativamente até a maturação final.

O coeficiente de respiração de crescimento dos frutos $\left(\mathrm{G}_{\mathrm{R}}\right)$ foi alto inicialmente $\left(0,53 \mathrm{~g} \mathrm{CO}_{2} \mathrm{~g}^{-1} \mathrm{MS}\right)$, dos 10 aos 24 DAA, decrescendo e tornando-se praticamente constante da fase de crescimento acelerado até a maturação final do fruto (Tabela 3), com um $\mathrm{G}_{\mathrm{R}}$ médio de $0,44 \mathrm{~g} \mathrm{CO}_{2} \mathrm{~g}^{-1} \mathrm{MS}$.

A taxa de respiração de crescimento dos frutos $\left(\mathrm{T}_{\mathrm{RG}}\right)$ foi estimada a partir da composição química do fruto ao longo do seu desenvolvimento (Figura 2). $\mathrm{T}_{\mathrm{RG}}$ aumentou da fase inicial de crescimento até a metade da fase de crescimento acelerado, alcançando o valor máximo de $256 \mathrm{mg} \mathrm{CO}_{2}$ fruto $^{-1} \mathrm{dia}^{-1}$ (75 DAA), decrescendo gradativamente até a completa maturação do fruto. A média de $\mathrm{T}_{\mathrm{RG}}$ foi de $194 \mathrm{mg} \mathrm{CO}$ fruto $^{-1}$ dia $^{-1}$ para o completo ciclo de desenvolvimento do araçá.

\section{CONCLUSÕES}

1 - Os teores dos macronutrientes (cálcio, fósforo, potássio, magnésio e nitrogênio) dos frutos decrescem ao longo do desenvolvimento dos frutos de araçá, sendo o nitrogênio o de maior valor.

2 - O conteúdo protéico decresce ao longo da ontogenia do fruto de araçá, e o teor de lipídios aumenta na fase de maturação do fruto.

3 - Os conteúdos de amido, carboidratos solúveis totais, açúcares redutores, lipídeos e ácidos orgânicos aumentam, enquanto os teores de proteína e os componentes da parede celular diminuem ao longo da ontogenia do fruto de araçá, principalmente na fase de maturação.

4 - Os carboidratos são os maiores componentes orgânicos do araçá, fazendo com que o custo da respiração de crescimento 

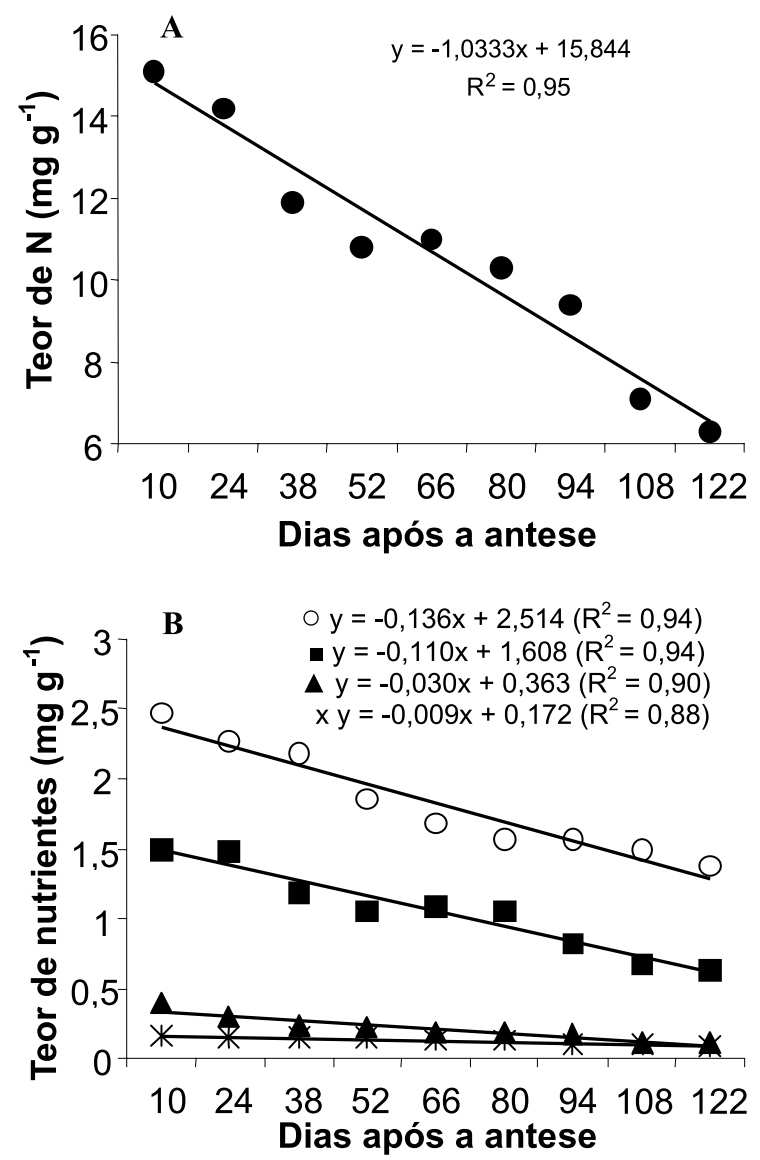

FIGURA 1- A) Teores de nitrogênio ( ), B) cálcio ( $\mathbf{\square})$, fósforo $(\mathrm{x})$, magnésio $(\boldsymbol{\Lambda})$ e potássio $(\mathrm{O})$.

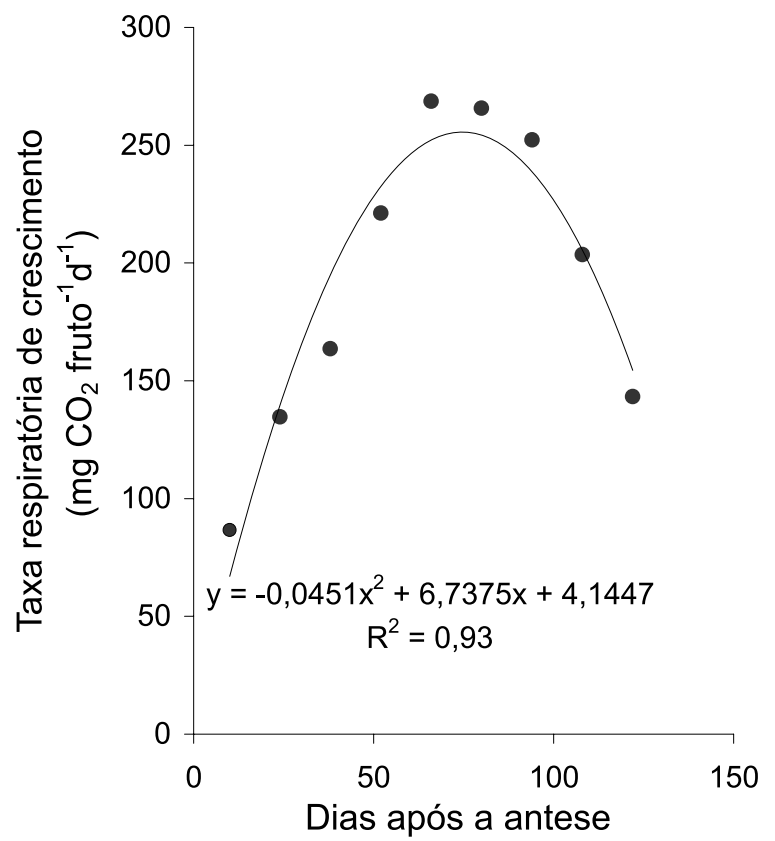

FIGURA 2 - Taxa de respiração de crescimento do fruto de araçá ao longo da ontogenia. dos frutos seja baixo. O fruto de araçá é eficiente na conversão de glicose em outros compostos orgânicos.

5 - O coeficiente de respiração de crescimento decresce com a idade do fruto de araçá. A taxa de respiração de crescimento incrementa até a metade do período de crescimento acelerado do fruto.

\section{REFERÊNCIAS}

AKAMINE, E.K.; GOO, T. Respiration and ethylene production in fruits of species and cultivars of Psidium and species of Eugenia. Journal of the American Society for Horticultural Science, Alexandria, v.104, n. 4, p. 632-635, 1979.

AOAC - ASSOCIATION OF OFFICIAL ANALYTICAL CHEMISTS. Official methods of analysis. $12^{\text {th }}$ ed. Washington, D.C., 1975. 1094p.

BRAGA, J.M.; DEFELIPO, B.V. Determinação espectrofotométrica de fósforo em extratos de solos e plantas. Revista Ceres, Viçosa, v.21, n.113, p.73-85, 1974.

CLEGG, K.M. The application of the anthrone reagent to the estimation of starch in cereals. Journal of the Science of Food and Agriculture, London, v.7, n.1, p. 40-44, 1956.

CZYRHINCIW, N. Tropical fruit technology. Advances in Food Research, San Diego, v.17, p.153-214, 1969.

GALHO, A.S.; LOPES, N.F.; RASEIRA, A.; BACARIN, M.A. Crescimento do fruto de araçá (Psidium cattleyanum Sabine). Revista Brasileira de Fruticultura, Jaboticabal, v.22, n.2, p.223-225, 2000.

INSTITUTO ADOLFO LUTZ. Normas Analíticas do Instituto Adolfo Lutz. $3^{\circ}$. ed. São Paulo- SP, 1985. 533p.

JOHNSON, C.M.; ULRICH, A. Analytical methods for use in plant analysis. Santa Barbara: University of California, California Agricultural Experimental Station, 1959. 1956p. (Bulletin, 766).

JORGENSEN, S.S. Laboratory manual: some methods used for routine chemical analysis. Centro de Energia Nuclear na Agricultura: Piracicaba, SP, 1977.22p.

LINDNER, R.C. Rapid analytical methods for some of the more common inorganic constituents of plant tissues. Plant Physiology, Rockville, v.19, n. 1, p. 76-89, 1944.

McCREADY, R.M.; GUGGOLZ, J.; WENS, H.S. Determination of starch and amylase in vegetables. Analytical Chemistry, Washington, v. 22, n.11, p.1156-1158, 1950.

NASCIMENTO, L.M.; SANTOS, R.R.; RIBEIRO, I.J.A.; MARTINS, F.P.; YOTSUYAMAGI, K; COUTINHO, J.R. Caracterização físico-química dos frutos de 23 cultivares de goiabeira (Psidium guajava L.) durante o processo de maturação. I. Coloração da casca, textura, sólidos solúveis totais, acidez total titulável e pH. Revista Brasileira de Fruticultura, Cruz das Almas, v.13, n. 3, p.25-34, 1991.

OGATA, J.N.; YOSHIHIKO, K.; BEVENU, A.: CASARETT, L.J. The keptoheptose content of some tropical fruits. Journal of Agricultural and Food Chemistry, Easton, v.20, n.1, p. 113-121, 1972. 
PAIVA, M.C.; MANICA, I.; FIORAVANÇO, J.C.; KIST, H. Caracterização química dos frutos de quatro cultivares e duas seleções de goiabeira. Revista Brasileira de Fruticultura, Cruz das Almas, v.19, n. 1, p. 57-63, 1997.

PENNING DE VRIES, F. W.T. Use of assimilates in higher plants. In: COOPER, J.F. (Ed.). Photosynthesis and productivity in different environments. London: Cambridge University Press, 1975b. p.459-480.

PENNING DE VRIES, F.W.T. The cost of maintenance in plant cells. Annals of Botany, London, v. 39, n. 1, p. 77-92, 1975a.

PENNING DE VRIES, F.W.T; BRUNSTING, H.M.; VAN LAAR, H.H. Products, requirements and efficiency of biosynthesis: A quantitative approach. Journal of Theoretical Biology, London, v. 45, n. 3, p.339-377, 1974.

PENNING DE VRIES, F.W.T; VAN LAAR, H.H. Simulation of plant growth and crop production. Wageningen: Pudoc, 1982.

PINHEIRO, R.V.R.; MARTELETO, L.O.; SOUZA,A.C.G.; CASALI, V.W.D.; CONDÉ, A R. Produtividade e qualidade dos frutos de dez variedades de goiaba, em Visconde do Rio Branco, Minas Gerais, visando ao consumo e à industrialização. Revista Ceres, Viçosa, v. 31, n. 177, p. 360-387, 1984.

PRUTHI, J.S. Physico-chemical composition of passion fruit (Passiflora edulis Sims). II. Varietals differences. Indian Journal of Horticulture, Lucknow, v. 15, n. 1, p. 87-93, 1938.

RASEIRA, M.C.B.; RASEIRA, A. Contribuição ao estudo do araçazeiro (Psidium cattleyanum). Pelotas: EMBRAPA/ CPACT, 1996. 95p.

RATHORE, D.S. Effect of season on growth and chemical composition of guava fruits. Journal of Horticultural Science, London, v. 51,n. 1, p. 41-47, 1976.

UMBREIT, W.W.; BURRIS, R. H.; STEAUFFER, J.F. Manometric and biochemical techniques. $5^{\text {th }}$ ed. Minneapolis: Burges, 1972.387p.

VAN SÖEST, P.J. Use of detergents in the analysis of fibrous feeds. I. Preparation of fiber residues of low nitrogen content. Journal of the Association Official of analytical Chemists, Arlington, v. 46, n.5, p. 825-835, 1963.

VAN SÖEST, P.J. Use of detergents in the analysis of fibrous feeds. III. Study of effects of heating and drying on yield of fiber and lignin in forages. Journal of the Association Official of analytical Chemists, Arlington, v. 48, n. 5, p. 785$790,1965$.

VAN SÖEST, P.J. Use of detergents in the analysis of fibrous feeds. IV Determination of plant cell wall constituents, Journal of the Association Official of analytical Chemists, Arlington, v. 50, n. 1, p.50-55, 1967.

WILSON, C.W. Guava. In: NAGY, S.; SHAW, P.F (Ed.). Tropical and subtropical fruits. Westport: AVI Publishing, 1980. 279p. 